\title{
USER-CENTERED DESIGN IN AGILE METHODOLOGIES
}

\section{O DESIGN CENTRADO NO USUÁRIO NAS METODOLOGIAS ÁGEIS}

\author{
Lara da Costa Brito ${ }^{1}$, M.Sc. \\ Manuela Quresma ${ }^{2}$, D.Sc.
}

(1) LEUI | Laboratório de Ergodesign e Usabilidade de Interfaces, PUC-Rio | Pontifícia Universidade Católica do Rio de Janeiro larbrit@gmail.com

(2) LEUI | Laboratório de Ergodesign e Usabilidade de Interfaces, PUC-Rio | Pontifícia Universidade Católica do Rio de Janeiro mquaresma@puc-rio.br

User-centered design, User experience, Agile methodologies.

Nowadays, although the user experience is considered a differential in the development of digital products, research, ideation, and evaluation activities are compromised in the user's research. This article aims to investigate the study of users aligned with the application of agile methodologies in the development of digital products in the Brazilian market.

Design centrado no usuário, Experiência do usuário, Metodologias ágeis.

Atualmente, embora a experiência do usuário seja considerada um diferencial no desenvolvimento de produtos digitais, as atividades de pesquisa, ideação e avaliação são comprometidas na pesquisa com usuários. Este artigo tem como objetivo investigar o estudo de usuários alinhados à aplicação de metodologias ágeis no desenvolvimento de produtos digitais no mercado brasileiro.

\section{Introduction}

Nowadays, the user experience is highlighted as a differential in the digital interface products and services market, known as User Experience (UX). Designing for the user experience requires many skills from the UX professional ${ }^{1}$, and to research user's requirements and satisfy their needs, it is necessary to include steps such as observing, analyzing, designing, and evaluating the product through the use of User-Centered Design (UCD).

Several challenges are faced by UX professionals to apply research with users through the adoption of UCD practices and establish a human-centered design culture in an agile design context. The problems start with the need for participation and involvement of users in a scenario of constant changes and speed in deliveries in product development. The research with users, according to Sauro (2016), includes the use of several Design methods, generating quantifiable results, through the systematic study of the objectives and abilities of those who use the system.

The impossibility of user involvement may affect the experience drastically as a whole since enough time and planning for the application of UCD practices are need to do user research. According to ISO 9241-210: 2010, whenever a design process is adopted, the human-centered approach must follow principles where user involvement is essential. Often the requirement provided by the user is simply neglected, thus compromising the quality of the experience, even if designed by specialists.

The hypothesis states that research with users is, according to what is recommended by the principles

\footnotetext{
${ }^{1}$ Multidisciplinary professionals who design for user experience (UX).
} 
of human-centered design, neglected in the application of agile methodologies. The theory explores the main aspects that configure user research through the principles enunciated by ISO9241-210 (2010) on Human-Centered Design for Interactive Systems. The goal of this research, therefore, is to investigate the application of usercentered design practices and research with users in the development of digital interface products and services, according to the principles of ISO 9241, in agile methodologies.

\section{User-centered Design on Agile Methodologies}

The joint work of UCD approaches and agile methodologies represents a significant corporate challenge that involves a mutual understanding of agile culture as well as the human-centered design culture. To make this union possible, it will be up to the UX professionals, the development teams, and the client ${ }^{2} s$ to support the task of integrating these approaches, taking advantage of their benefits, and adding value to products and user experience.

\subsection{User-centered Design and the User Experience}

User-centered design is an approach to collecting and analyzing user requirements. According to ISO 9241-210: 2010 on human-centered design for interactive systems:

Human-centered design is an approach to the development of interactive systems that aims to make systems usable and useful, focusing on users, their needs and requirements, and applying human factors/ergonomics and usability knowledge and techniques. (ISO 9241-210: 2010, p. vi).

Norman (2013) states that User-Centered Design is a philosophy. It suggests having a good understanding of people through observations to promote a real understanding of their needs, considering that individuals do not always know their actual demands and difficulties. In this way, the philosophy of User-Centered Design adds an indepth knowledge about human needs to the design processes, regardless of the product or focus on being followed. Baxter et al. (2015) emphasize that the UCD doctrine is that the product needs to serve the user, instead of waiting for the user to adapt to the product and this is only possible with the use of methods, techniques, and processes centered on the user.

As stated by Hartson, Pyla (2012), the design of an interface can be simple, but what does not make it simple is the design to provide a good experience, which needs to apply the practices that involve usercentered design. According to the User Experience Professionals Association (UXPA), user experience as a discipline is related to all the elements that together make up an interface including layout, visual design, text, brand, sound, and interaction. For Hartson, Pyla (2012):

User experience is the totality of the effect or effects felt by a user as a result of interaction with, and the usage context of, a system, device, or product, including the influence of usability, usefulness, and emotional impact during interaction, and savoring the memory after interaction. "Interaction with" is broad and embraces seeing, touching, and thinking about the system or product, including admiring it and its presentation before any physical interaction. (Hartson, Pyla, 2012, p.5).

Regarding the experience as a broad picture, when well designed, it can also benefit enterprises by the quality of the products they develop, as a differentiating element among competitors, becoming a strong appeal to the digital market.

For Norman (1986), from the user's point of view, the interface is the system itself and, therefore, must have attributed to meet their needs. The usercentered design highlights that the primary purpose of a system should not be around technology, but rather in helping the user.

Considering the user experience, despite the benefits involved in designing products, Norman (2013) notes that the user-centered design exposes the ideal process. Still, in business practice, UX professionals are compelled to prioritize other needs. Companies often believe in UCD practices, however, for the development of new products, there is a corporate trend to match up with the competitors, due to the market, and the use of new technologies. Thus, development ends up interfering even in companies that believe in user's feedback, mainly due to insufficient time and budget when launching products.

\footnotetext{
${ }^{2}$ Person or organization which demands services.
} 


\subsection{User Centered Design Principles}

ISO 9241-210: 2010 is responsible for providing the requirements and recommendations for activities and principles and their projects throughout the life cycle of interactive systems. Regardless of the design process, responsibility, or roles adopted, the user-centered approach must follow the following principles according to ISO 9241-210: 2010:

1. The design should be based upon an explicit understanding of users, tasks, and environments: products and services should be designed, taking into account both users and stakeholders, therefore needing to be identified. There should be an explicit understanding of the user's usage context, including goals, tasks, and the environment. Inadequate or incomplete knowledge of user needs is a source of system failures.

2. Users should be involved in the entire design development process: involvement provides knowledge about the context of use and the task. It should be active, whether acting as a data source or evaluating solutions. Those involved in the process should have skills, characteristics, and experience that reflect the extent of the users.

3. The design should be driven and refined through user-focused evaluations: the evaluation and improvement of design through users based on their feedback provides a minimizing risk that a system will not meet the user's needs, allowing design solutions to be tested in real-world scenarios.

4. The process should be iterative: iteration should be used to eliminate uncertainties when developing interactive systems. Iterations enable that descriptions, specifications, and prototypes are revised and refined as new information is gathered, minimizing the risk that the system under development does not meet the user's requirements.

5. The design should address the whole $U X$ : the user experience is a direct consequence of the presentation, functionality, system performance, interactive behavior, and the capabilities of a system (hardware and software).

6. The design team should have multidisciplinary skills: UCD teams should behave diversified skills to collaborate on the design and implementation decisions, taking into account areas of expertise such as human factors and ergonomics, usability, accessibility, human interaction -computer, among others.

When the need to develop a system, product or service is identified through a user-centered design approach, the following activities must be applied during the design of an interactive system, according to ISO 9241-210: 2010:

- Understand and specify the context of use: the context of the use of a system can be defined through the characteristics of users, tasks, and the technical, physical, and organizational environment. It is essential to gather and analyze all information about the current context to understand and then specify the context that will be applied to the future system. Analyzing similar software provides information on a range of issues in a context, and can reveal needs and problems that need to be detected before building a new system. If there is a record of user feedback, reports, and other data, this may provide a basis for prioritizing changes and improvements to the system.

- Specify user requirements: The activity of identifying users 'needs and specifying functional requirements should be increased to create a statement of users' requirements about the intended context of use and the business objectives of the system. Depending on the scope, user requirements may include requirements for organizational changes. If the interactive system affects corporate practices, the development process must involve stakeholders to improve both the company and the system.

- Produce design solutions that meet user requirements: design solutions can have a significant impact on the user experience. The human-centered design aims to achieve a good user experience considering it throughout the design process. The production of design solutions must consider the creation of user tasks, interactions between user and system, and take into account the entire user experience. Also, you must implement the design solutions through prototypes or scenarios, change the solutions in response to user-centered evaluations, and communicate the design solutions to those responsible for implementation.

- Evaluate projects versus requirements: usercentered evaluation is an activity required in Human-Centered Design. Even in the early stages of the project, design concepts must be 
evaluated to gain a better understanding of users' needs. A system can be very complicated, and only with an evaluation through the actual use of the product can provide user-centered understanding.

The principles of ISO 9241 state about the explicit understanding of users, their involvement in the process of developing a project, and about userfocused evaluations, among others. These principles, combined with activities to understand the context of use, specify user requirements, produce design solutions and evaluate design concepts, can guarantee that a product or service obtains a solution centered on the needs and requirements of users.

\subsection{Agile Manifesto}

Currently, agile methodologies dominate the development of products entirely. For Sommerville (2011), agile methods allow the team to focus on the software and not on its documentation, based on an incremental development for product specification and delivery. The term "Agile Development" emerged from the Agile Manifesto as an alternative development process so that agility could be incorporated into projects and thus combat slow and bureaucratic software delivery.

The Manifesto (2001) states the following values for the development of agile software:

- Individuals and interaction more than processes and tools

- Software working more than comprehensive documentation

- Collaboration with the client more than contract negotiation

- Responding to changes rather than following a plan

The values emphasize the need to prioritize the professional's involvement (individuals and clients) and their means of interaction, as well as the getting results (software working), attentive to the scenario, and adapting to changes in software development. The values of agile development are complemented by the following principles of the Agile Manifesto (Table 1):

\begin{tabular}{|c|c|}
\hline Principles & Characteristics \\
\hline $\begin{array}{l}\text { 1. Our highest priority is to } \\
\text { satisfy the customer through } \\
\text { continuous and early delivery } \\
\text { of value-added software. }\end{array}$ & $\begin{array}{l}\text { Quality software delivery } \\
\text { Fast and continuous } \\
\text { iterations } \\
\text { Adds business value to the } \\
\text { customer }\end{array}$ \\
\hline $\begin{array}{l}\text { 2. Changes in requirements } \\
\text { are welcome, even late in } \\
\text { development. Agile } \\
\text { processes take advantage of } \\
\text { the changes aiming at a } \\
\text { competitive advantage for the } \\
\text { client. }\end{array}$ & $\begin{array}{l}\text { Favorable condition for } \\
\text { change through the use of } \\
\text { techniques and tools } \\
\text { Rapid response to } \\
\text { transformation needs } \\
\text { Client minimizes the risk of } \\
\text { making hasty decisions }\end{array}$ \\
\hline $\begin{array}{l}\text { 3. Deliver frequent working } \\
\text { software, from a few weeks } \\
\text { to a few months, with a } \\
\text { preference for the shortest } \\
\text { time scale. }\end{array}$ & $\begin{array}{l}\text { Through time-boxes, the } \\
\text { team can predict how much it } \\
\text { produces in each cycle } \\
\text { The project develops through } \\
\text { iterations of continuous } \\
\text { improvement Both the client } \\
\text { and the team members } \\
\text { increase their confidence } \\
\text { during the project. }\end{array}$ \\
\hline $\begin{array}{l}\text { 4. Business people and } \\
\text { developers must work } \\
\text { together daily throughout the } \\
\text { project. }\end{array}$ & $\begin{array}{l}\text { Adopts a collaboration } \\
\text { process between customers } \\
\text { and teams, working together, } \\
\text { in the same environment } \\
\text { Continuous flow of discussion } \\
\text { and feedback }\end{array}$ \\
\hline $\begin{array}{l}\text { 5. Build projects around } \\
\text { motivated individuals. Give } \\
\text { them the environment and } \\
\text { support they need and trust } \\
\text { them to get the job done. }\end{array}$ & $\begin{array}{l}\text { Self-managed agile teams } \\
\text { The direct and constant } \\
\text { communication environment } \\
\text { Feedbacks are frequent } \\
\text { The commitment of the whole } \\
\text { team }\end{array}$ \\
\hline $\begin{array}{l}\text { 6. The most efficient and } \\
\text { effective method of } \\
\text { transmitting information to a } \\
\text { development team through } \\
\text { face-to-face conversation }\end{array}$ & $\begin{array}{l}\text { The objectivity of a face-to- } \\
\text { face conversation should not } \\
\text { be replaced by electronic } \\
\text { communication } \\
\text { The most recommended type } \\
\text { of information exchange is } \\
\text { face-to-face communication } \\
\text { The less indirect contact, the } \\
\text { lower the risk of conflict }\end{array}$ \\
\hline $\begin{array}{l}\text { 7. Working software is the } \\
\text { primary measure of progress. }\end{array}$ & $\begin{array}{l}\text { The progress of a software } \\
\text { project must be measured, } \\
\text { through the amount of } \\
\text { software delivered and in } \\
\text { operation } \\
\text { Do not measure by the } \\
\text { volume of documents } \\
\text { generated }\end{array}$ \\
\hline $\begin{array}{l}\text { 8. Agile processes promote } \\
\text { sustainable development. } \\
\text { Stakeholders, developers, } \\
\text { and users must be able to } \\
\text { maintain a constant pace } \\
\text { indefinitely. }\end{array}$ & $\begin{array}{l}\text { The work environment must } \\
\text { operate within the operational } \\
\text { limits of the resources } \\
\text { involved } \\
\text { Sustained levels of high } \\
\text { productivity must be feasible } \\
\text { within periods }\end{array}$ \\
\hline $\begin{array}{l}\text { 9. Continuous attention to } \\
\text { technical excellence and } \\
\text { good design increases agility. }\end{array}$ & $\begin{array}{l}\text { Well-executed code } \\
\text { combined with a quality } \\
\text { project eliminates the need } \\
\text { for exhaustive } \\
\text { documentation, reduces } \\
\text { rework and facilitates quick } \\
\text { decision making } \\
\text { Enabling constant deliveries } \\
\text { and quick responses to } \\
\text { customer feedbacks }\end{array}$ \\
\hline $\begin{array}{l}\text { 10. Simplicity - the art of } \\
\text { maximizing the amount of } \\
\text { work not done - is essential. }\end{array}$ & $\begin{array}{l}\text { Few features reduce design } \\
\text { complexity } \\
\text { Ease of maintenance } \\
\text { More time available for the } \\
\text { improvement and }\end{array}$ \\
\hline
\end{tabular}




\begin{tabular}{|c|c|}
\hline & $\begin{array}{l}\text { implementation of other } \\
\text { higher-value functionality }\end{array}$ \\
\hline $\begin{array}{l}\text { 11. The best architectures, } \\
\text { requirements, and designs } \\
\text { emerge from self-organizing } \\
\text { teams. }\end{array}$ & $\begin{array}{l}\text { It is needed to maintain the } \\
\text { synchronism between the } \\
\text { team in the face of changes } \\
\text { The team must know how to } \\
\text { reorganize itself to keep the } \\
\text { basic rules established valid }\end{array}$ \\
\hline $\begin{array}{l}\text { 12. At regular intervals, the } \\
\text { team reflects on how to } \\
\text { become more active and } \\
\text { then refines and adjusts its } \\
\text { behavior accordingly. }\end{array}$ & $\begin{array}{l}\text { At each cycle, the team } \\
\text { reflects on what has been } \\
\text { done, learns from what did } \\
\text { not work and leverages what } \\
\text { is working } \\
\text { Each team, in each project, } \\
\text { must seek its work dynamics, } \\
\text { with no pre-established rules } \\
\text { The basic rule is continuous } \\
\text { improvement }\end{array}$ \\
\hline
\end{tabular}

Table 1: Principles of the Agile Manifesto. Source: Prikladnicki et al. (2014).

Accurately, the agile principles propose a work dynamics whose main objective is to maintain the client's satisfaction, involving him in the whole development process. Through incremental deliveries, the motivated team develops, accepting changes, not letting this condition affect the product, which must preserve its simplicity, eliminating complexity.

\subsection{Agile development versus UCD practices}

According to Beyer (2010), to understand the agile culture, it is needed to learn the language and attitude of agile development and thus apply its values and principles. The new values bring opportunities to integrate UCD practices into the agile process. Agile cultural values have a direct influence on the working relationship between UX professionals and developers. Beyer defines the values of agile culture and points of attention for the UX team (Table 2):

\begin{tabular}{ll}
\hline There is only one team & \\
\hline $\begin{array}{l}\text { General Points } \\
\text { The entire team is }\end{array}$ & UCD points \\
responsible for everyone's & $\begin{array}{l}\text { UX professionals need to } \\
\text { educate the team about UCD } \\
\text { practices and what may be } \\
\text { work }\end{array}$ \\
\begin{tabular}{ll} 
If a part of the project has a & needed to design an interface \\
problem, it is everyone's & UX professionals are part of \\
problem & the client team, supporting \\
The team needs to work well & the P.O or product owner ${ }^{3}$ \\
together, ideally in a single & \\
room & \\
Everyone on the team should & \\
be able to work on any part & \\
\hline
\end{tabular}
\end{tabular}

3 Product Owner plays the role of prioritizing lists of product requirements. of the product

\section{User is part of the team}

General Points

The user is considered a member of the team, represented by the product owner (in the Scrum ${ }^{4}$ method)

Some teams may assume that the end-user may be part of the team

Planning can be a waste of time General Points

From an agile point of view, changes in requirements will exist, and as a consequence, there will be changes in goals It is better to do something small quickly, get feedback and develop without general planning, than to spend a lot of time on planning that will never be implemented

Face-to-face communication General Points

Written documentation is obsolete as soon as it is written and does not usually have efficient communication The agile value signals the benefit of end-users talking directly to the development team that is building the product

UCD points

Much of the ideation work must take place before the development work starts (phase zero)

The goal at this point is to design and validate the proposed product so that user stories can be written with confidence

The UX team can run a flow parallel to the iterative development process, saving up sprint timebox ${ }^{5}$

\section{is better than documentation} UCD points

It should be part of the routine to encourage daily discussions with team members on how to implement the user interface for user stories

UX professionals should have shared documentation, containing sketches and studies, avoiding user interfaces already defined

Short sprints are good. Shorter sprints are better

\section{General Points UCD points}

The work of an agile team is At the end of a sprint, user composed of structured sprints. Each sprint ends with the construction of a full version of the product. Agile methods assume that work can be started and completed in a single sprint, and agile teams tend to believe that shorter sprints are better than longer ones. interfaces must be operational and comply with standards

The entire team should be interested in ensuring that UX work is done as part of the sprint

If there is not enough time to do user interviews and prototypes in the same sprint as the implementation, it is acceptable to divide the user experience work into a separate story

Continuous feedback guides the project

\section{General Points UCD points}

Get feedback on each sprint The UX team member has as it is developed. This feedback ensures that the project is on track Promote feedback sessions at the end of a sprint, with a quick step by step of the product with comments and the skills to obtain real user feedback in the iterative process Actual work validation requires the team to test the product with users in their work context, applying
${ }^{4}$ Scrum is an agile method for managing and planning software projects

${ }^{5}$ Time scale defined by the project sprint. 
reactions collected and

recorded.

examples of their tasks

Table 2: Values of agile culture and UCD points. Source: Beyer (2010)

Through the values of agile culture, it can be observed that the development of agile products in association with UCD practices has several points of attention so that it is possible to maintain the balance between the approaches, thus guaranteeing the quality of users' requirements. According to the points highlighted by Beyer, the main challenges for the integration of UCD practices with agile culture to be overcome are:

- Agile methods do not address the product ideation phase. Often, the decision of the problems to be solved and prioritized is made by the team and stakeholders, without collecting user requirements

- Agile methods do not provide specific techniques to support parts of the user interface such as structure, interface elements, layout and screens

- The duration of the sprints (from two to four weeks) is a real challenge for research activities with users. UX professionals should always try to work on sprints ahead of the product team

Although agile practices offer multiple benefits for product development, Laubheimer (2017) argues that they were focused on developers/programmers in an attempt to solve problems generated during project development. The Agile Manifesto did not, therefore, include concerns about collecting user requirements or planning the time needed to conduct research to design for the user experience in software development, creating a gap about the user experience in agile methodologies. Such gaps can only be filled by an initiative to integrate agile and UCD methods.

\section{Research Methods and Techniques}

To collect information about the problem and validate the hypothesis, the field research used data collection techniques that allowed the analysis of qualitative and quantitative data. To explore aspects of how UX professionals use UCD practices to the development of digital products, semi-structured interview technique, and an online questionnaire were applied with professionals who work with agile methods in companies of digital interface products and services in Brazil.

\subsection{Semi-structured interviews}

The goal of the interview was to understand how practices related to user-centered design are performed in companies, according to the methodologies for developing digital interface products in Brazil. Among the advantages listed by Marconi and Lakatos (2017), the interviews offer opportunities that evaluate attitudes through the registration of the interviewee's opinions, gather data that is not found in documentary sources, and allow the data to be subjected to statistical treatment. The semi-structured interview technique provided the freedom to explore significant aspects of enterprises and how they deal with UCD practices in design methodologies.

\subsubsection{Participants}

The interviews were attended by 25 professionals who deal directly with UCD practices in companies with digital interface products in Brazil. Due to the multidisciplinary nature, the professional training area did not prevent the selection of the profile, as long as it acted with UCD practices. The participant's profiles brought together different levels of experience (junior, full, senior), occupying positions as designers, leaders, managers, and CEOs.

\subsubsection{Procedures}

The structuring of the interview script was defined through questions that sought to identify and understand the relationship between UCD practices with professionals, managers, teams, product development methodologies, processes, and projects from the perspective of the interviewee. Thus, it was possible to investigate how these UCD practices are perceived, prioritized, managed, and performed in the daily lives of teams and corporations. The script covered general and specific subjects about the interviewees, the company, the performance team, the management of the departments, and the working methods and techniques, as shown below (Table 3):

\begin{tabular}{ll}
\hline Activities & Addressed issues \\
\hline $1 . \quad$ Introduction & $\begin{array}{l}\text { Introduce yourself. Inform about the } \\
\text { objective of the interview/research } \\
\text { Inform the expected duration of the } \\
\text { interview (45 min) } \\
\text { Show the consent form and ask for } \\
\text { permission to record }\end{array}$ \\
\hline
\end{tabular}




\begin{tabular}{|c|c|}
\hline $\begin{array}{l}\text { 2. About the } \\
\text { participant and the } \\
\text { company }\end{array}$ & $\begin{array}{l}\text { Company working and number of } \\
\text { employees } \\
\text { Time working for the company } \\
\text { Position/function held and time of } \\
\text { experience in the position/function } \\
\text { Main responsibilities }\end{array}$ \\
\hline $\begin{array}{l}\text { 3. About the team, } \\
\text { management, and } \\
\text { projects }\end{array}$ & $\begin{array}{l}\text { Official team and/or department to } \\
\text { design UX } \\
\text { Professionals who make up the team } \\
\text { Figure of the manager responsible for } \\
\text { UX } \\
\text { Perception of other areas of the } \\
\text { company in relation to the work that } \\
\text { the team develops } \\
\text { Internal promotion of the work } \\
\text { performed by the team } \\
\text { Moment of the project that begins the } \\
\text { work of UX } \\
\text { Project carried out by the team that } \\
\text { has caught the attention of company } \\
\text { leaders } \\
\text { The budget allocated to the team } \\
\text { (resources, training, tools) } \\
\text { Measurement of UX return on } \\
\text { investment (ROI) }\end{array}$ \\
\hline $\begin{array}{l}\text { 4. About working } \\
\text { methods and } \\
\text { techniques }\end{array}$ & $\begin{array}{l}\text { Products and services that usually } \\
\text { work } \\
\text { UX methods, techniques and tools } \\
\text { used } \\
\text { How products and services are } \\
\text { developed }\end{array}$ \\
\hline 5. Final discussion & $\begin{array}{l}\text { End with summary } \\
\text { Thank you for your participation } \\
\text { Ask about availability for a future } \\
\text { conversation and request contacts }\end{array}$ \\
\hline
\end{tabular}

Table 3: Script of the semi-structured interview.

\subsubsection{Conducting the interviews}

The interviews were conducted from May to September 2018. As the survey should have a national scope, the interviews were conducted in person and remotely, at a time and place convenient for each participant. The sessions lasted approximately 45 minutes. The results were revealing, and similarities were found regarding the difficulties faced in the professionals' daily lives and also diversified ways to solve problems in different contexts. The main concern between interviewees was related to the lack of time and planning for the development of user research, showing that it can be challenging to design for the user experience and maintain the quality of the products. These perceptions served as inputs to guide the next stage of the research, complementing the qualitative data collection through the questionnaire.

\subsection{Questionnaire}

The questionnaire was chosen as a data collection technique to provide a national reach survey according to the goal of identifying how the research with users is made, following the principles of ISO 9241, applied to agile methodologies, in the Brazilian market. The questionnaire was designed according to Gil (2002) recommendations such as the use of specific questions, avoiding subjective answers, respect for the participant's privacy, and the use of an introduction to inform about research details.

To verify that user research is applied suitably with agile methodologies, the following principles of ISO-9241-210 (2010) on Human-Centered Design for Interactive Systems were considered:

- The design should be based upon an explicit understanding of users, tasks, and environments;

- Users should be involved in the entire project development process;

- The design should be driven and refined through user-focused evaluations.

The questionnaire gathered questions regarding design methodologies, acting roles, corporation characteristics, user requirements, user research, user involvement, and user feedback, providing a broad view of how professionals research with users in the daily life of an agile context.

\subsubsection{Procedures}

After drafting, a pre-test was made to refine and improve the questions. Marconi and Lakatos (2017) point out that after preparing a questionnaire, there is a need to evaluate it in a small population, showing possible flaws and ambiguities.

The pilot had seven respondents and, after the pretest, feedbacks were gathered, allowing adjustments on the inquires objectivity and clarity regarding agile methodologies. After validating changes, the final version was composed of 27 questions. The questionnaire attends the following representation, according to the addressed questions: 


\section{Ergodesign \& HCI}

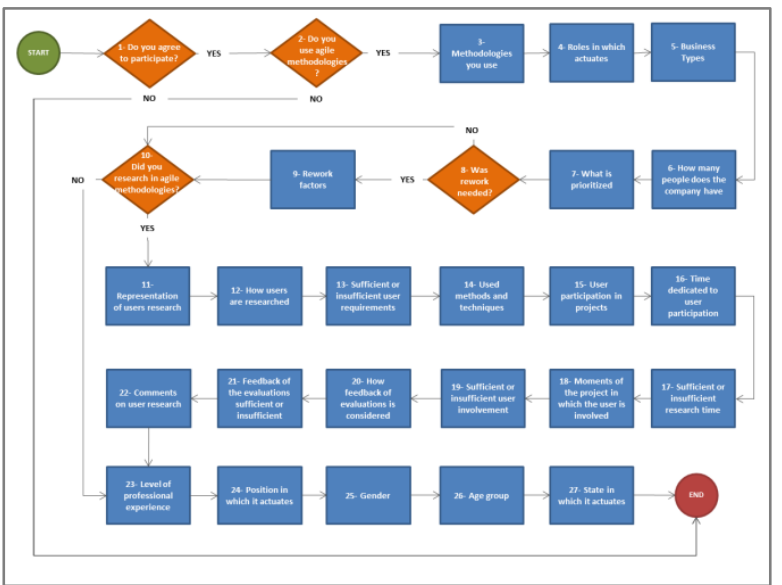

Figure 1: Representation of the questionnaire applied to the research.

The questionnaire is represented by dichotomous questions that help to determine whether the respondents can join the study or not. One of the first inquiries is about the use of agile methods. If the answer is "no," they will finish the research, demonstrating not being part of the sample. If the answer is yes, after going through the sections on methodologies, projects, and companies, they will find the next conditional question on participation in projects where there has been any rework. If the respondents answer yes, they proceed to a specific question. Still, if they answer no, they are driven to the next conditional question about researching with users in agile methodologies. If the answer is yes, the respondents go on to the section on user research in agile methods. However, if not, they are taken to the last part of the participant's data, not being discarded from the study.

\subsubsection{Questionnaire application}

The online questionnaire was available from October 18 to November 19, 2018, and had a total of 226 respondents. The survey was sent via email, social media such as Facebook and Linkedin and messaging applications such as WhatsApp and Telegram, in addition to specific forums on agile methodologies, design, and software quality. The selected target audience for sending the invitations was composed of professionals from all levels of experience, from interns to seniors who work or have worked in the development of digital interface products with agile or design methodologies.

Among the 226 respondents, about $90 \%$ use or have used agile methodologies against 10\% who did not. Approximately $67 \%$ answered all questions in the
PUC-Rio Pontifícia Universidade Católica do Rio de Janeiro Departamento de Artes \& Design | PPGDesign

LEUI | Laboratório de Ergodesign e Usabilidade de Interfaces

questionnaire. Of the research participants, the majority act as a designer (54\%), followed by a researcher $(28 \%)$, P.O (24\%), project manager and information architect (22\%). Regarding the participation of projects using research with users in agile methodologies, $74 \%$ responded positively against $26 \%$ who did not use it.

\section{Results Analysis}

\subsection{Interview results}

The interviews were recorded on audio and then analyzed immediately after each session for data collection. Answers were reviewed, complementing the notes made during the sections. The 25 participants received identification from P1 to P25. After comparing the responses, it was possible to observe the frequencies according to the grouping established for the questions and to highlight the respondent's opinions through the challenges and problems faced.

\subsubsection{About the participant and the enterprise}

The first section of the interview collected general data about the professional and the company, such as the position/function held, the number of company employees, location, and primary responsibilities. According to the data collected, the interviewees work in the Brazilian market in companies ranging from small to large, located in the states of Rio de Janeiro, São Paulo, Amazonas, Rio Grande do Sul, Pernambuco, and Santa Catarina. Most of the participants have worked in the current company for about two years, and the positions held are Product Designers, UX Designers, UX Researchers, Head of UX, and UX Managers.

\subsubsection{About the team, management and projects}

The section covered specific topics and questions about the organization of UX teams, UX management and projects as described below:

- Regarding the UX professional qualification, there was a diversified, multidisciplinary scenario and different levels of experience, with a significant presence of seniors and juniors.

- Regarding the presence of a UX manager, although there is the figure of a manager, sometimes he is not fully dedicated to the UX demands, sharing the management with other 
departments and product teams.

- Concerning the perception of the work of the UX team, it is possible to notice that the company recognizes it. Still, it is restricted to the departments that have the closest contact.

- About the moment when UX work begins, the interviewees said that the moment might vary according to the project, and usually, it starts late.

- Concerning the budget for the team, most of the participants stated that there was some kind of budget, but not necessarily dedicated to the UX team.

- Regarding the return on investment (ROI) of UX, the measurement is not carried out regularly due to the difficulty in quantifying it, and the lack of knowledge on how to measure it.

\subsubsection{About the ways of working}

The last section raised details on how products and services are developed, described as followed:

- The products and services mentioned were portals, intranets, social networks, teaching platforms, mobile platforms, web, retail systems, health, and innovation products.

- The most cited practice was the agile methodology, with an emphasis on the Scrum method.

- The most referred design methodologies were user interviews and the usability test and, in a smaller number, the questionnaire. Qualitative methods are the most used. However, quantitative methods arouse the interest of UX professionals due to their adapting to agile methodologies.

- Regarding the way products and services are developed, it was possible to conclude the need for time for conducting in-depth research.

Respondents reported that if the analysis is made on time, including the compilation of data, it can effectively assist decision-making, especially as support for agile methodologies, which proposes short iterations.

\subsection{Questionnaire results}

The questionnaire had a total of 226 respondents, most of them from the state of Rio de Janeiro (48\%) and São Paulo (32\%). As for gender, males represented $57 \%$ and females $43 \%$. The age group with the highest participation was 26 to 35 years
(42\%), followed by 36 to 45 years (30\%). The highest level of professional experience was senior $(52 \%)$, followed by full (27\%), junior (11\%) and trainee/trainee (5\%), declaring themselves in various positions as analysts, consultants, developers, designers, specialists, managers, leaders, researchers, and programmers. Of the total respondents (226), 90\% declared that they had already used agile methodologies in interface projects. Regarding the number of professionals who participated in projects using research with users in agile methodologies, $74 \%$ stated that they had already used it, and $26 \%$ stated that they had not (Figure 2).

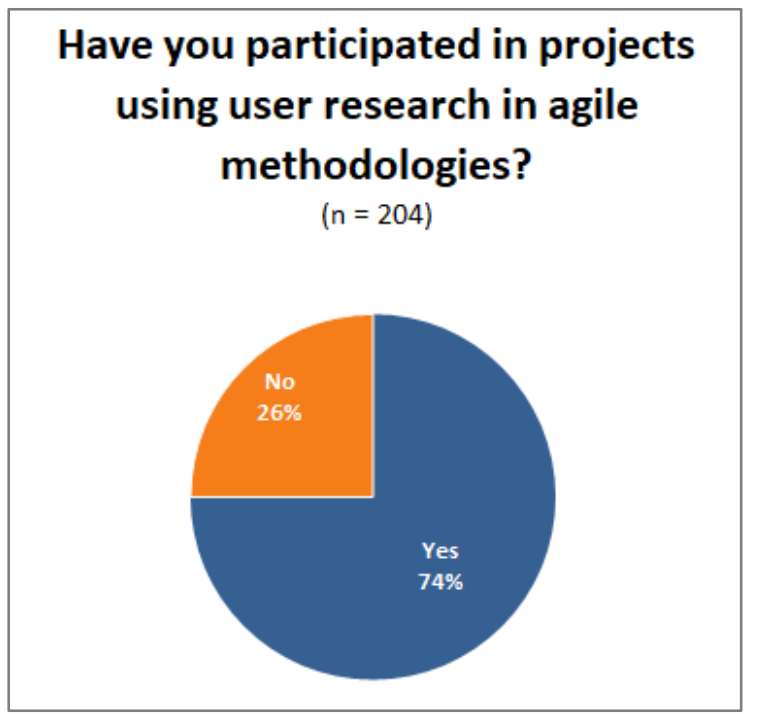

Figure 2: Percentage of research participation with users in agile methodologies.

An arrangement of the collected data was performed for the analysis of the responses, where relevant questions were selected (related to the principles of ISO 9142) that would assist in the fulfillment of the research goals. After this prior organization, the data were filtered according to the answers. Then the key questions were related to the characteristics of the professionals and companies (project methodologies, roles, among others). Design Sprint, Scrum, Lean, Extreme Programming, Design Thinking, Waterfall, and hybrid approaches were considered methods and design approaches. By crossing data from these questions, it was possible to perform their interpretation and to get the study results. 


\subsubsection{Gathering user requirements in agile methodologies}

A data crossing was performed to understand how the requirements gathering is made in project methodologies (Graphic 1). In general, the agile methodologies (Design Sprint, Scrum, Lean, and Extreme Programming (XP)) present similar values between the types of analyzed gathering, proving that use both users and clients in the same way, to perform the requirements gathering.

The result partially meets the first principle that, according to ISO 9241-210: 2010, recommends an explicit understanding of users, tasks, and environments. In product development, it is required to consider who will use the product.

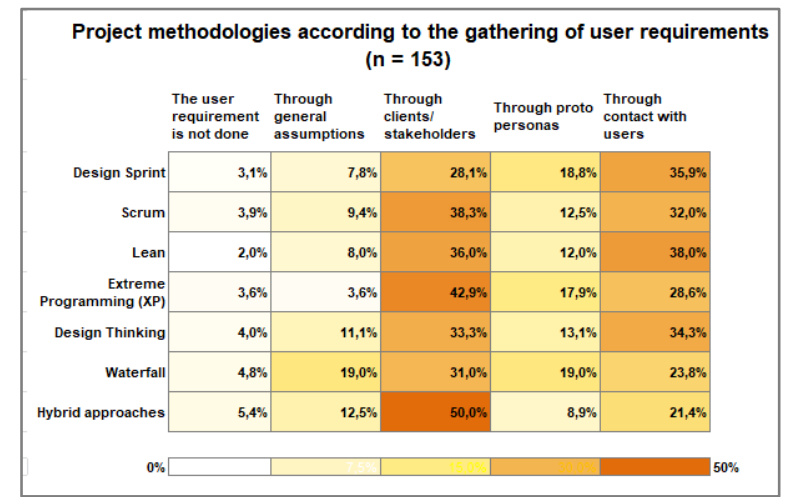

Graphic 1: Percentage of project methodologies according to the user requirements.

\subsubsection{User participation in agile methodologies}

The design methodologies data was crossed with the type of the user's involvement data to analyze the users' participation in projects (Graphic 2).

Practically all the project methodologies, including agile, have statistically the same values between the types of participations except for the Extreme Programming (XP).

Through the data collected, it is concluded that agile methodologies employ users with specified profiles in the same proportion as "easily accessible users for participation in the projects," "the client playing the role of the user," and "the client indicating the user." The result partially meets the first principle, which, according to ISO 9241-210: 2010, is based on an explicit understanding of users, tasks, and environments, where it is needed to consider who will use the product (the user). Through these results, the user competes with the other types of participation in projects.

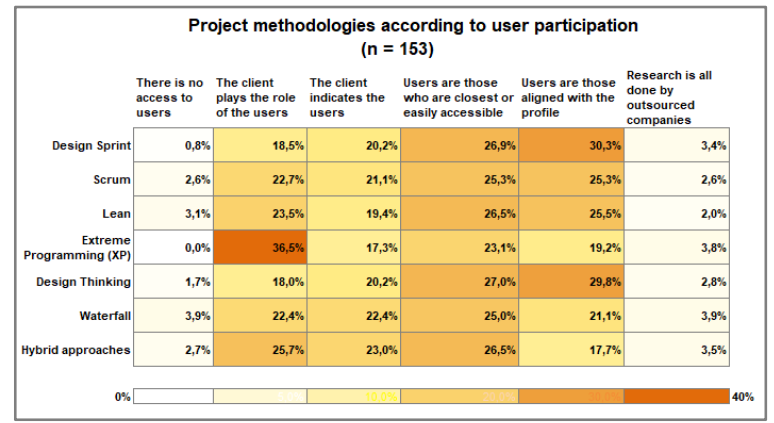

Graphic 2: Percentage of project methodologies according to the user's participation.

A data crossing was performed to analyze how the roles of the project team influence the user's involvement in projects (Graphic 3). It is possible to notice that the distribution by roles provides a differentiated analysis from that performed by the methodologies. It is noteworthy that the role of scrum master has the highest use of "clients as users." Perhaps this is due to several factors: confusion between the figure of the client and the user, lack of prioritization of research with users, lack of time for the participation of users, and the team's little ability to research with users. According to the data analysis, this result does not meet the first principle of ISO 9241-210: 2010, which considers users who will use the product in the specified profile.

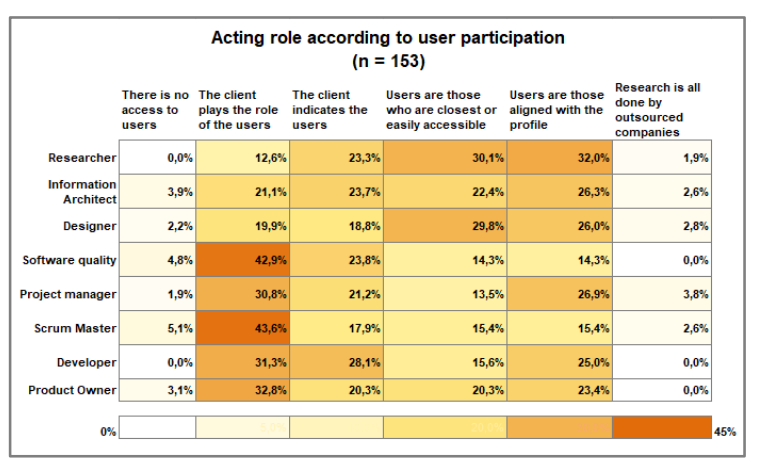

Graphic 3: Percentage of acting roles according to the user's participation.

\subsubsection{User involvement in agile methodologies}

A data crossing was performed to understand the moment of users' involvement in project methodologies (Graphic 4). In general, agile 
methods expose similar values for almost all responses except "at no time," which has low representation. Through the data presented, it is verified by the second principle of ISO that the results partially meet the moment of user involvement in agile methodologies.

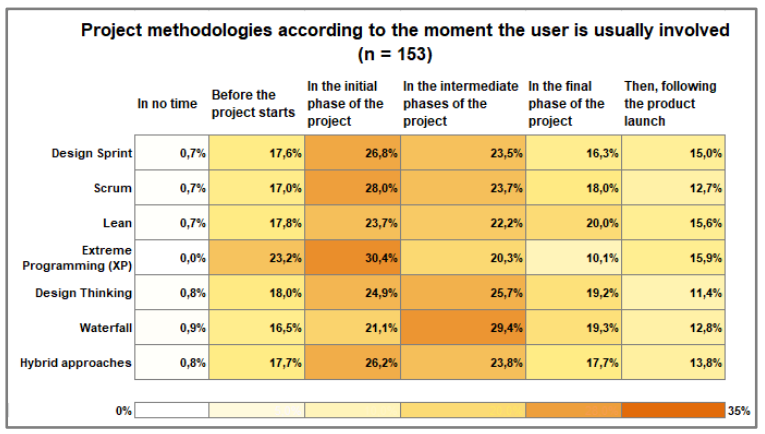

Graphic 4: Percentage of project methodologies according with the moment of user involvement.

\subsubsection{User feedback in agile methodologies}

A data crossing was performed to analyze the user's feedback in agile methodologies (Graphic 5). In general, the majority of methods, including agile, consider user feedback widely in agile methods, representing the option with the highest number of responses.

According to ISO 9241-210: 2010, the third principle states that the development of systems must consider and be conducted through evaluations with users, minimizing the risks of not meeting their needs. Therefore, the results evidence that they are following the third principle.

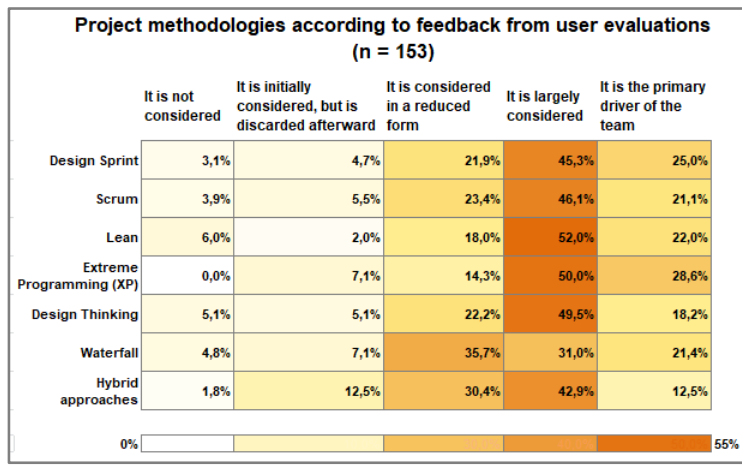

Graphic 5: Percentage of project methodologies according to user feedback.

\section{Conclusion}

User-Centered Design is an approach widely spread by the Design community, especially among professionals in the field who contribute to disseminate its concepts and principles. Although it is a widespread reality, the application of its practices does not, in itself, guarantee an excellent interface. Still, it can promote substantial improvements in a product, avoiding possible failures according to its principles.

This study aimed to analyze the difficulties, contexts, and challenges found by UX professionals in companies and teams to research with users in design methodologies and agile development. It was needed to establish an understanding of how UX professionals, inserted in the context of the teams, deal with project development processes, as well as how they develop UCD practices and how much they interact with agile methodologies when researching with users to prove the hypothesis.

According to the application of the principles of ISO 9241, considering the use of agile methodologies and their acting roles applied to requirements gathering, user participation, the moment of user involvement and user feedback, the hypothesis is partially proven for statistical purposes, given the similarities and differences of the data presented.

It can be concluded that although the agile methodologies are performed in reduced cycles of time, it is possible to meet the principles of UCD in product development partially. It is worth considering, however, that the presence of "palliative" solutions such as the use of clients instead of users, in statistical similarity to the recommendations pointed out by the ISO principles, becomes a worrying factor. Although the hypothesis has been partially proven, it is worth highlighting the adaptations of UCD practices to the immediate needs of projects that require a deadline for fulfillment of deliveries and does not provide the support needed for UX professionals to plan user's research. As a possible solution, the best way would be to prepare before the project starts, foreseeing the need for research with the time needed to perform, avoiding work overloads before the UX team and professionals. 


\section{References}

BAXTER, Kathy; COURAGE, Catherine; CAINE, Kelly. Understanding your users: A practical guide to user research methods. Morgan Kaufmann, 2015.

BEYER, Hugh. User-Centered Agile Methods. Morgan \& Claypool Publishers, 2010.

HARTSON, R.; PYLA, P. The UX Book: Process and Guidelines for Ensuring a Quality User Experience. Morgan Kaufmann, 2012.

ISO 9241-210 (2010) ISO 9241-210. Ergonomics of Human-System Interaction-Part 210: HumanCentred Design For Interactive Systems.Génève: International Organization Standardization, 2010.

LAUBHEIMER, Page. Agile Is not Easy for UX: (How to) Deal with It, 2017. Disponível em: < https://www.nngroup.com/articles/agile-not-easyux/>. Acesso em: 21/11/2018.

MANIFESTO para desenvolvimento ágil de software. [S.1: s.n.], 2001. Disponível em: < https://agilemanifesto.org / $>$. Acesso em: $01 \mathrm{dez}$. 2018.

NORMAN, Donald. The design of everyday things: Revised and expanded edition. Basic Books (AZ), 2013.

PRIKLADNICKI, Rafael; WILLI, Renato; MILANI, Fabiano. Métodos ágeis para desenvolvimento de software. Bookman Editora, 2014.

SAURO, Jeff; LEWIS, James R. Quantifying the user experience: Practical statistics for user research. Morgan Kaufmann, 2016.

SOMMERVILLE, Ian. Engenharia de software. Tradução Ivan Bosnic e Kalinka G. de O. Gonçalves; revisão técnica Kechi Hirama -. 2011.

\section{Acknowledgments}

This article was made with the support of the Coordination for the Improvement of Higher Education Personnel - Brazil (CAPES) - Financing Code 001 and the National Council for Scientific and Technological Development (CNPQ). 